\title{
44533 - EPIDURAL ANESTHESIA DECREASES ICU UTILISATION AND COSTS AFTER ELECTIVE OFF-PUMP CABG SURGERY
}

\author{
David Bracco, Montreal General Hospital, Montreal, QC, Canada; \\ Nicolas Noiseux, Hotel Dieu de Montreal; \\ Ignacio Prieto, Hotel Dieu de Montreal; \\ Fadi Basile, Hotel Dieu de Montreal; \\ Thomas M Hemmerling, Montreal General Hospital;
}

\begin{abstract}
INTRODUCTION:
Epidural anesthesia has been proposed as an adjunct to allow operating room extubation. Epidural anesthesia has potential benefits on the time to extubation, hemodynamic stability and respiratory function. The aim of this prospective observational cohort study was to measure the immediate post-operative resource utilization in the ICU in elective off-pump CABG (OP$\mathrm{CABG}$ ) patients receiving or not an epidural catheter for pain control.
\end{abstract}

METHODS:

Local IRB approval was obtained for this study. 3 out of 3 cardiac surgeons and 6 out of 13 anesthesiologists performed epidural anesthesia (T2-4, bupivacaine $0.125 \% 6-14 \mathrm{ml} / \mathrm{h}$ up to 3 days postop) for cardiac surgery cases when not contraindicated. Cases were evenly attributed between anesthetists due to billing reasons. Prospective data acquisition of peri-operative data by the PeriCARG database and the ICU computerized database. Analyses were done by intention to treat and costs were retrieved from previously published data.

\section{RESULTS:}

Over 3.5 years, a total of 902 consecutive elective OP-CABG were evaluated: 357 in the epidural and 545 in the control group. There were no differences in the pre-operative data, number of grafts and duration of ischemia and surgeries. Patients with an epidural catheter could be extubated earlier and required less ICU resources. Epidural catheter leads to a $40.5 \%$ decrease in ICU costs. 


\begin{tabular}{|l|c|c|c|}
\hline & Control group & Epidural group & P \\
\hline Length of ICU stay (days) & $1.97(1.55-2.39)$ & $1.25(0.89-1.60)$ & $<0.02$ \\
\hline Requiring ventilation (\% of patients) & $61 \%$ & $8 \%$ & $<0.001$ \\
\hline Length of ventilation (hours) & $14.9(10-19.8)$ & $3.6(0-9.6)$ & $<0.005$ \\
\hline Total number of laboratory panel ordered (n/pts) & $6.23(4.88-7.58)$ & $4.63(2.90-6.36)$ & NS \\
\hline Arterial blood gases in the ICU (n/patient) & $2.29(2.01-2.56)$ & $1.74(1.36-2.11)$ & $<0.01$ \\
\hline Transfused (\% of patients) & $20 \%$ & $18 \%$ & NS \\
\hline Volume blood transfused (ml/patients) & $345(240-451)$ & $196(86-305)$ & $<0.05$ \\
\hline Total ICU costs (US \$/patient) & 14121 & 8402 & $<0.0001$ \\
\hline Mechanical ventilation costs (US \$/patient) & 4360 & 1047 & $<0.0001$ \\
\hline
\end{tabular}

There were no epidural related complications.

\section{CONCLUSIONS:}

Epidural anesthesia leads to substantial reduction in ICU resource use and costs savings. An average cardiac surgery service performing 500 OP-CABG cases per year performing half of them under combined general-epidural will spare 2800 hours of mechanical ventilation, 180 ICU days and 1,4 millions US \$ a year. 